\title{
Analysis Of 3g Uk Mobile Industry And Comparison With Vodafone Network Based On Consumer Satisfaction Survey.
}

\author{
M.s Priya Vij \\ (Department of Business Management, Padmashree Dr.D.Y.Patil University, India)
}

\begin{abstract}
Marketing is used to identify the customer, to keep the customer and to satisfy the customer. With the customer as the focus of its activities, it can be concluded that marketing management is one of the major components of business. This study focuses why marketing strategies and planning are important in today's world. Markets are made up of customers with wants and needs. Market planners must provide products and services that are better than those which competitors offer. The organization with the most effective marketing strategy should become the market leader. This project also focuses on mobile industry of UK and its revenue generation. It also provides information on various types of marketing strategies that are used by $3 G$ as well as its pricing policies and product service. There is survey conducted on Consumer satisfaction for $3 G$ and Vodafone. Comparison focuses on the pricing policies of both companies' products as well as overall experience with the products. The objective of the study to do a comparative analysis with Vodafone UK and to find marketing strategies conducted by $3 G$ and to understand marketing strategies better. Moreover to have an overview on the UK mobile industry. The Research Methodology is based on primary data and secondary data. The methodology used involved interaction with the concerned people in organization and study of various documents and guidelines pertaining to the same.

$3 G$ is also called third generation. It is named as such because it is the third generation of the standards of telecommunication hardware. It is also the general technology for mobile networking, passing the recent 2.5G. The technology is founded on the ITU or International Telecommunication Union group of standards which belongs to the IMT-2000.The significant contribution of this paper is that $3 G$ market-driving forces are likely to be high data speed with mobile Internet access, mobility, multimedia facilities, video conferencing, etc and $3 G$ wireless technology provides an exciting new development in the way people communicate with each other. It enables us to use a much more comprehensive range of communication than previous forms. Moreover because of the greater bandwidth the new technology offers, there are tremendous benefits to be gained by business and private users. Features such as high-speed internet connections and the transmission of pictures and sound give users access to high-quality information wherever they are.
\end{abstract}

Keywords: Marketing Strategies, Mobile Internet access, Multimedia, technology, telecommunications

I.

Introduction

Twenty years ago, when the mobile phone industry started in the UK, phones were the size and the shape of bricks. They were expensive fashion items for well-heeled City types and did only one thing: make phone calls. The huge progress since is thanks largely to a progressive, deregulated environment, and the work of some pioneers and evangelists who understood where mobile might take us. There are now more mobile phones than UK citizens- 63 million at the last count. These phones are capable of amazing things. Playing music, checking email and playing games are standard practice. It is still evolving incredibly fast. Three years ago there were only a handful of significant companies operating outside the network operators' world, now there are hundreds. A recent survey by $\mathrm{O}$, conducted in conjunction with Real Business, identified more than 200 independent firms that were creating innovative mobile products and services for businesses and consumers. The survey's list of 50 companies to watch, published this week, accounts for nearly $£ 1 \mathrm{bn}$ in revenues in the past year - a sign that mobile is no longer just a poor relation to mainstream telecoms and internet technologies, but an industry in its own right. The implications for UK business are vast. Companies on the 50 to watch list are in some of the fastest-moving and most profitable markets, helping the likes of Google, Disney, Coca-Cola, Ford, Cisco and Visa to develop marketing strategies based on mobile technologies. Aggregators such as WIN (Wireless Information Network) are building applications that save companies significant amounts of money. Companies such as Volantis are helping companies such as the FT, Egg, Norwich Union, Interflora, Ladbrokes and dozens of others to create fully functional mobile versions of their services. Experienced IT directors know how difficult it is to build useful, working mobile applications, and they know they need reliable business partners Opera Telecom, the biggest aggregators in the UK, reported revenues of $£ 99 \mathrm{~m}$ in 2004, with a $£ 6 \mathrm{~m}$ profit. And these firms are well-placed to support UK and international businesses. As GSM access expands to more than 200 countries and two billion users, a vast export market is emerging. 
In some organizations that innovation is being expressed in relatively simple applications, such as PCto-text services that allow managers to communicate quickly and effectively across entire mobile workforces without leaving their desk. It is being found in live financial services that let people manage their bank accounts or insurance policies, or to share trades securely from mobile devices. And in other cases it is creating new retail channels that break the reliance on costly outlets and call centers. No organization can ignore mobile for much longer. The bigger issue is what you do with it, and how you blend it with existing technology and processes to ensure a sustainable fit.UK companies have come a long way in helping people address those issues. There is no better place to be building mobile products and services, and there is no better way to help organizations give themselves an edge, not just in local markets but internationally too.

\section{Objective of the Study}

This study is done in order to achieve the following objectives:-

$>$ To do a comparative analysis with Vodafone UK.

$>$ To have an overview on the UK mobile industry.

$>$ To analyze whether it is possible for $3 \mathrm{G}$ in order to compete in other regions of the world.

\section{Research Methodology}

Research Methodology for preparing this project is primary data and secondary data. The methodology will be use for preparing this report involved interaction with the concerned people in organization and study of various documents and guidelines pertaining to the same.

\section{"3.1, Primary Data"}

It is used for analyzing the objectives and collecting the first hand feedback from customers. This work will be carried out through face to face interviews.

\section{"3.1.1, Sample size"}

The total no. of consumers interacted is 30 .

\section{"3.1.2, Sampling type"}

Random sampling Information obtained from online survey conducted for consumers who are currently using $3 \mathrm{G}$ and Vodafone services. It also contains information obtained through surveys, interviews and observations.

\section{"3.2, Secondary data"}

Secondary data implies reusing the data that someone has already collected to support one's analysis.

The documents used

- Magazines

- Annual reports

- Brochures

- Articles on Marketing Management and Strategies.

\section{Review of Literature}

A detailed survey of the concerned literature has been carried out based on various journals; books and internet are presented below. Strategic Management and Marketing by Narendra Singh This is the latest book covering two subjects together i.e. "Strategic Management" and Marketing. The important overages in this book are Strategic Management, Area of Strategic Management and Sales and marketing Management - concepts and practices as an important activity of the business organization linking with the strategic Management.

Marketing Strategy A Decision - Focused Approached by Walker Boyd and Mullins Larreche. The text covers the concepts and theories of creating and implementing a marketing strategy. A process of strategic Planning shows students what planning processes and analytical tools and techniques are involved in formulating, implementing, and controlling a strategic marketing program.

Marketing Strategy and Competitive Positioning by Graham J. Hooley, John A. Saunders, Nigel F. Piercy Marketing Strategy and Competitive Positioning deals with the process of developing and implementing a marketing strategy. The third edition focuses on competitive positioning at the heart of marketing strategy and includes in-depth discussion of the processes used in marketing to achieve competitive advantage.

The websites visited are www.3g.co.uk, www.vodafone.co.uk, www.mobilein.com/3G.htm, www.three-g.net/3g_standards.html 


\section{UK Mobile Operator Subscriber Data, Statistics And Market}

Five mobile network operators are identified in the UK by 'The Worldwide Directory of Mobile Network Operators 2008'. The UK market consists of 4 geopolitical areas, namely England, Scotland, Wales and Northern Ireland. For mobile phone purposes, various islands also have their own operators, such as the Isle of Man (located in the Irish Sea between North West England and Ireland); and the Channel Islands, notably Jersey and Guernsey.

At the end of 2007 the UK had some 73.1 million mobile subscribers, which represented 9 percent of the European mobile subscriber market.IE Market Research Corp. has reported that the overall subscriber base in UK is still increasing, and the number of total subscribers will change from our projected 75.9 million in 2008 to 78.0 million in 2010 , with wireless penetration expected to reach $126.0 \%$ in 2010 .

The five primary operators are 3G UK, Orange, T-Mobile, Telefonica $\mathrm{O} 2$ and Vodafone. In addition there are number of Mobile Virtual Network Operators (MVNO), the MVNO Directory claims there are some 41 organizations active in the sector. These range from conventional MVNOs through to resellers, and include well-known names such as Virgin Mobile and Tesco.

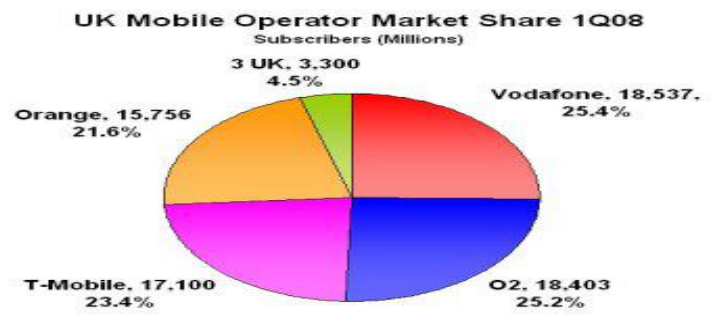

figure 1 Source: The Worldwide Directory of Mobile Network Operators 2008 c. 2008

Vodafone currently (1Q 2008) has the largest UK market share with $25.4 \%$ of the market. Vodafone watch newsletter provides an intimate snapshot of Vodafone, with SWOT, political analysis, market share, activities, communication opportunities, threats, political factors, company background and structure, management, revenue, market segmentation, market research on its peers, with a focus on Vodafone UK, its market share, and resumes of the Vodafone annual reports - all presented in one handy monthly newsletter format.

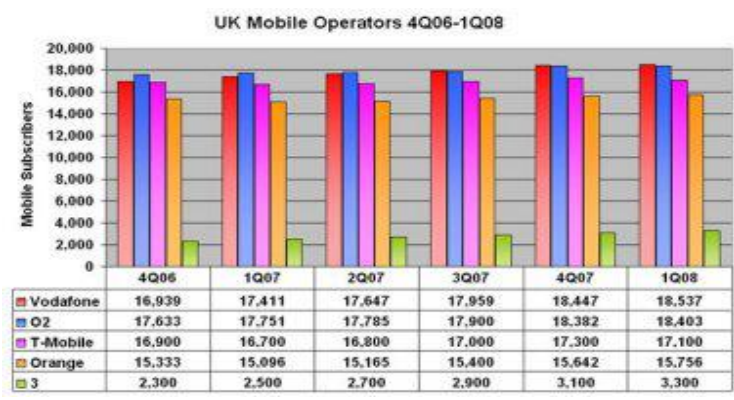

figure 2 Source: The Worldwide Directory of Mobile Network Operators 2008 c. 2008

Telefonica's O2 is a vibrant No. 2 in the market, only losing the the lead position in 3Q 2007. O2 is part of the Telefonica Group, and a new report -The Telefonica Report 2008: Strategy and Outlook 2008-11 provides timely analysis and insight into Telefónica's short- to medium-term strategy, incorporating a SWOTtype review. From Telefónica's future strategy perspective, the report covers the four-year period from 2008 to 2011.

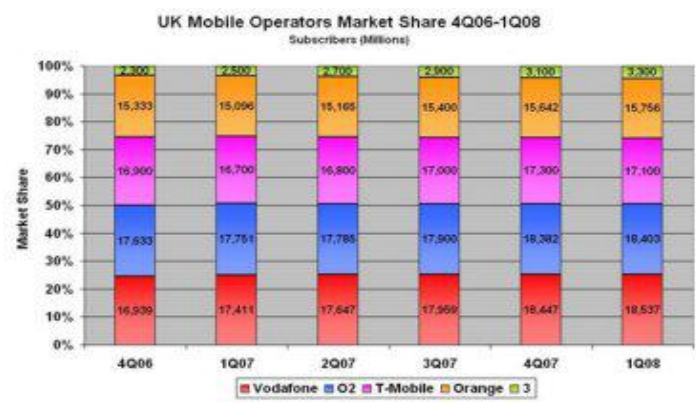

figure 3 Source: The Worldwide Directory of Mobile Network Operators 2008 c. 2008 
T-Mobile takes third place in this highly competitive market. To learn more about T-Mobile, and its home market, The German Telecommunications Report 2008 has been researched at source and features latestavailable data covering all headline indicators; 5-year industry forecasts through end-2012; company rankings and competitive landscapes covering leading Multinational handset manufacturers and equipment vendors, domestic fixed-line and mobile operators, and analysis of latest industry news, trends and regulatory developments.

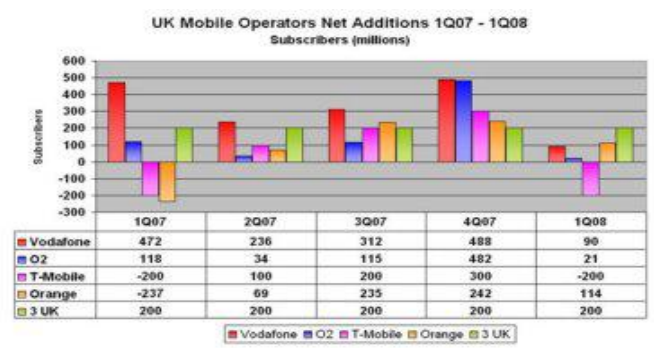

figure 4 Source: The Worldwide Directory of Mobile Network Operators 2008 c. 2008

The UK Telecommunications Report 2008 provides an at-a-glance outlook of the structure, size and value of the industry, including an overview of key players and a snapshot of regional penetration rates forfixed-line, mobile and internet markets.

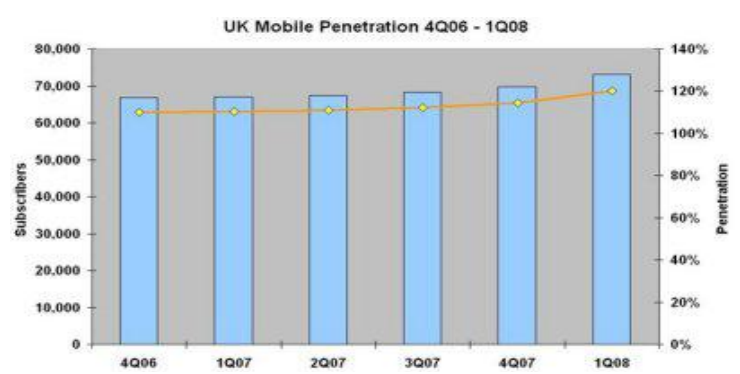

figure 5 Source: The Worldwide Directory of Mobile Network Operators 2008 c. 2008

\section{Defining 3G}

The mobile communication industry is currently shifting its focus from second generation networks (2G) towards the third generation networks (3G). The shift is not only related to the evolution of the access technology, but also to the vision of the development of service provisioning and service demands, customer expectations and customer differentiation. While current wireless networks still evolve and service providers bring new internet packet data services into the markets, an increasing number of operators and other wireless communication professionals are becoming familiar with the wideband code division multiple access (WCDMA) technology and prepare themselves for 3G services and networks. There will be a number of new challenges when shifting from the current $2 \mathrm{G}$ to the new

$3 \mathrm{G}$ networks, many of them related to the design and the operation of true multi-service radio networks. An essential part of the new challenges is related to the provisioning, monitoring and optimization of the services. The number of network counters and measurements shall increase owing to the fact that instead of monitoring GSM voice only, one must concentrate on monitoring multi system and multiservice environment.

$3 \mathrm{G}$ is also called third generation. It is named as such because it is the third generation of the standards of telecommunication hardware. It is also the general technology for mobile networking, passing the recent $2.5 \mathrm{G}$. The technology is founded on the ITU or International Telecommunication Union group of standards which belongs to the IMT-2000.3G networks allow network operators to provide users a bigger range of the latest services, as it gets bigger network capacity via heightened spectral efficiency. The included services are video calls, wide-area wireless voice telephone and broadband wireless information, all included within the mobile environment. More features incuded are HSPA data transmission capacities that can send data rates reaching 14.4 Mbit/s on the downlink and the uplink at 5.8 Mbit/s.

\section{History and Start}

The first 3G network offered for commercial use was launched in Japan by NTT DoCoMo. The network had the brand name FOMA and was introduced in May 2001 on a W-CDMA technology pre-release. The initial commercial launch of 3G was also done by NTT DoCoMo in Japan. This happened on October 1, 2001 , although the technology was still very limited in terms of scope at the beginning. The broad availability, due to inadequate reliability had to be delayed. 
SK Telecom from South Korea was the second network that was released commercially live. This was on the 1xEV-DO technology dated January 2002. In May 2002, the second 3G network from South Korea was on EVDO by KTF, posing Koreans as the first to view the competition of all $3 \mathrm{G}$ operators.

Isle of Man by Manx Telecom was the first pre-commercial network released from Europe. At that time, the operator went by the name British Telecom. Telenor opened the first commercial network in Europe for business in December 2001. There were no commercial handsets, however, so there were also zero clients. These were on the W- CDMA technology.

\section{An Introduction to 3G Technology}

$3 \mathrm{G}$ services for mobile devices have been introduced by various handset creators and cellular carriers. The companies, however, are not very good at explaining the exact details, except for a given few. There seems to be a missing link between the current standard from previous services provided by $2.5 \mathrm{G}$ or $2 \mathrm{G}$ technology. Knowing the types and details will help you pick the right tools for your personal use or business. Here are some features.3G cellular technology is defined as the provision of wireless broadband data and information services right to a person's mobile unit. Compared to the previous technologies, 3G promises speeds ranging from 144 $\mathrm{Kbps}$, which is 3 times faster compared to the traditional $56 \mathrm{~K}$ dial-up modem connection up to $2.4 \mathrm{Mbps}$, which is very near cable-modem speed. The networks of $3 \mathrm{G}$ allows you to browse quickly through web pages, watch ondemand video programs, download and play music, videos and 3D games, watch streaming videos and music videos and have a video conference with others located on the other side of the plant.

\section{The Accesses}

Currently, $3 \mathrm{G}$ technology is the most recent in mobile communications. $3 \mathrm{G}$ is the shorter term for third generation, making analogue cellular technology generation one and digital/PCS generation two. The 3G technology is planned and devised for the real multimedia cellular phone, also known as smart phones. These tools feature higher bandwidths and transfer rates to cater to web-based applications and phone-based video.

The most common include CDMA2000, which is based on code division multiple access, TD-SCDMA, which stands for Time-division Synchronous Code-division Multiple Access and WCDMA or UMTS which stands for Wideband Code Division Multiple Access.

\section{The Networks}

3G networks have the capability of transferring speeds up to $3 \mathrm{Mbps}$ which is equivalent to around 15 seconds for every download of a 3-minute MP3 song. To compare, the speediest 3G cellular phones can move speeds up to $144 \mathrm{Kbps}$, which is equivalent to around 8 minutes to download a 3-minute MP3 song. The high data rates of $3 \mathrm{G}$ are recommended when downloading or acquiring information online, as well as sending and receiving huge

multimedia files.

3G phones are comparable to small laptops that can cater to several broadband applications like browsing the internet, receiving streaming videos online, video conferencing and sending and receiving faxes. The soaring towers are among the most important element of the group, allowing the data to be transferred from one hone to another. $3 \mathrm{G}$ basically is a cellular

phone network protocol.

\section{Data Interpretation \& Analysis}

It was really a good experience to do this project from 3G. A set of closed ended questions were asked to the customers. I had got the various different answers from them. Firstly were the parameters for comparison with international standards norms. While coming to comparison with international network Vodafone UK there are various parameters that are needed to be considered like active consumer engagement and education through their retail stores and their marketing activities. $3 \mathrm{G}$ aims to help the regulator understand what can be done to help drive the future of mobile - what the mobile internet can and cannot do and how much it's going to cost. Let's see the data interpretation done on the basis of consumer satisfaction survey.

Consumer Satisfaction Survey for $3 \mathrm{G}$

\section{It was accessed that since how long $3 \mathrm{G}$ services have been used}

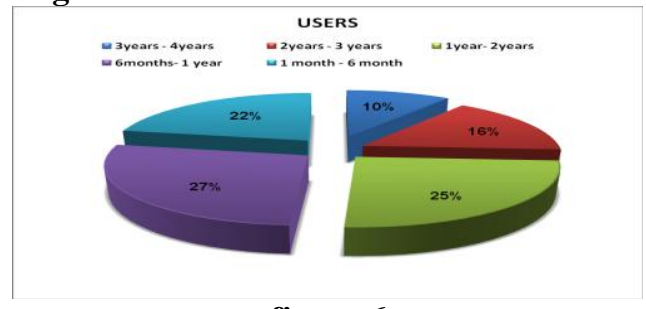

figure 6

www.iosrjournals.org 
Interpretation: It was observed that most of the users started using 3G services in less than 6 months.

It was accessed that how do the customers like the range of handsets provided by $3 \mathrm{G}$ ?

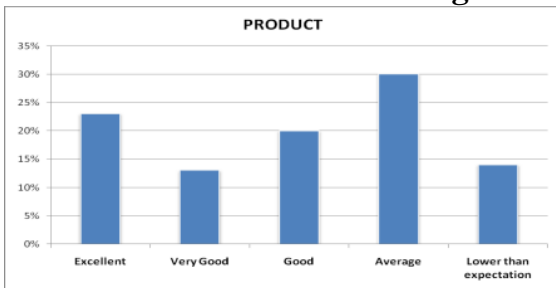

figure 7

Interpretation

It was observed that customers rated average for $3 \mathrm{G}$ handsets. Most of them didn't find any new changes in handset.

It was accessed that how do the customers find the network provided by $3 \mathrm{G}$ ?

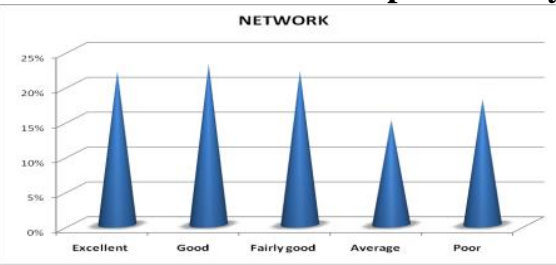

figure 8

Interpretation

It was observed that most of the consumer finds good network coverage from 3G.

It was accessed that how do you find the broadband service provided by $3 \mathrm{G}$

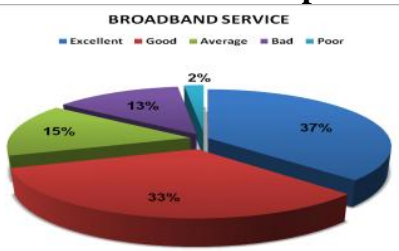

figure 9

Interpretation

It was observed that most of the consumer said that they get excellent broadband service from 3G.

It was accessed that if customers were given a chance, would you like to move to a different network from 3G

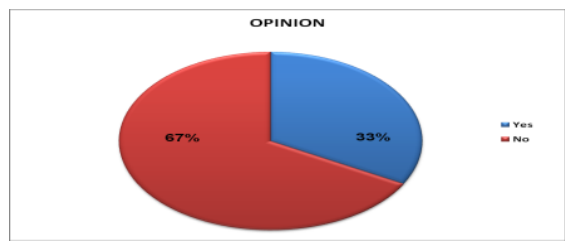

figure 10

Interpretation

It was observed that most of the consumer said no for changing their network from $3 \mathrm{G}$ to any other mobile service.

It was accessed that overall, how the customers would rate 3G in terms of mobile and broadband.

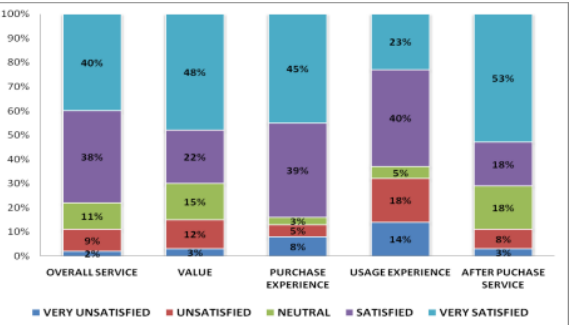

figure 11

www.iosrjournals.org 

Interpretation

It was observed that consumers are happy with customer service provided by $3 \mathrm{G}$ as well as they are satisfied with overall services provided by $3 \mathrm{G}$.

\section{Consumer survey with Vodafone UK}

It was accessed that since how long Vodafone services have been used

Interpretation

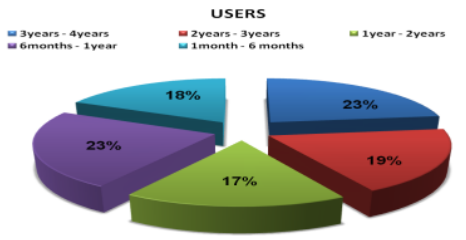

figure 12

It was observed Vodafone users are decreased in recent times as compared to 3G.

It was accessed that how do the customers like the range of handsets provided by Vodafone

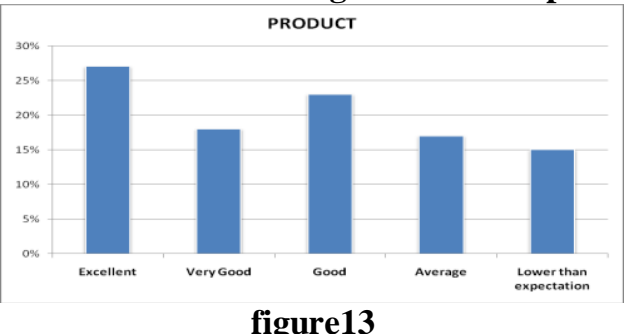

Interpretation

figure13

It was observed that Vodafone provides good handsets compare to 3G.

It was accessed that how do the customers find the network provided by Vodafone

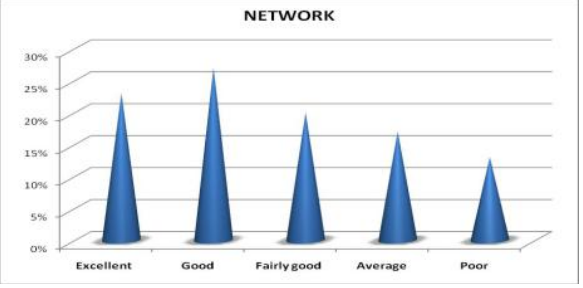

figure 14

Interpretation

It was observed Vodafone has less network coverage as compared to 3G.

It was accessed that how do you find the broadband service provided by Vodafone

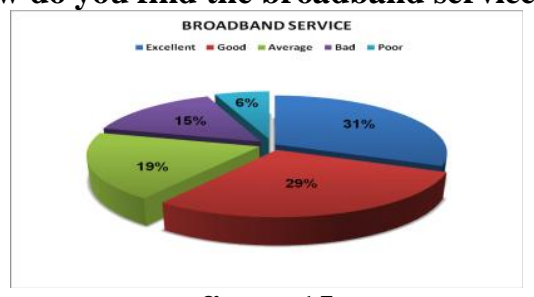

figure 15

Interpretation

It was observed that a consumer likes $3 \mathrm{G}$ broadband services more than Vodafone. 
Analysis of $3 G$ UK Mobile Industry and Comparison with Vodafone network based on Consumer It was accessed that if customers were given a chance, would you like to move to a different network from Vodafone.

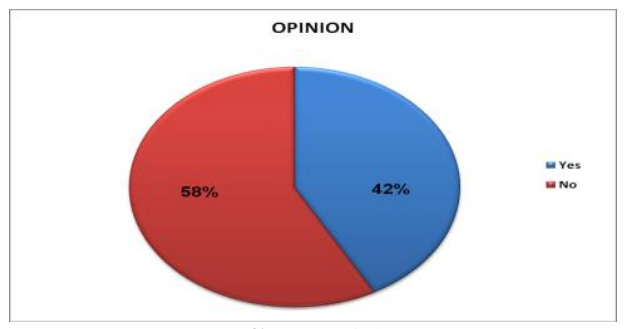

figure 16

Interpretation

It was observed that most of the consumers don't want to change their network but when we compare with 3G we observes that Consumer finds $3 \mathrm{G}$ network better.

\section{It was accessed that overall, how the customers would rate Vodafone in terms of mobile and broadband.}

Interpretation

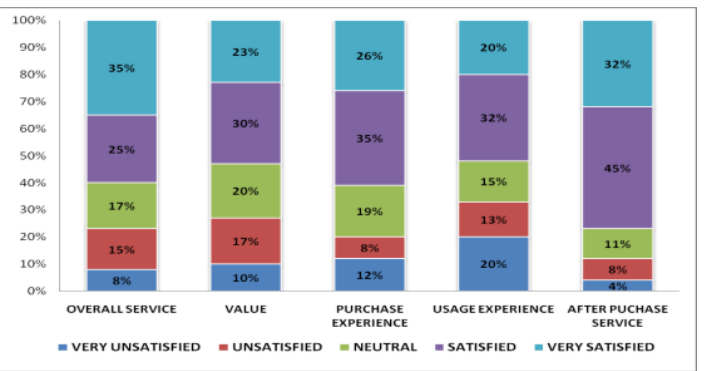

figure 17

It was observed that most of the people prefer $3 \mathrm{G}$ compared to Vodafone. We can see people get more network coverage while using $3 \mathrm{G}$.

\section{Conclusion}

* 3's market research shows that young people like 3G because it enables them to send pictures, view videos and listen to music downloads. It is also popular with business customers and people who work in the media - for example, film editors and journalists.

- 3G market-driving forces are likely to be high data speed with mobile Internet access, mobility, multimedia facilities, video conferencing, etc.

* 3G wireless technology provides an exciting new development in the way people communicate with each other. It enables us to use a much more comprehensive range of communication than previous forms.

* Because of the greater bandwidth the new technology offers, there are tremendous benefits to be gained by business and private users. Features such as high-speed internet connections and the transmission of pictures and sound give users access to high-quality information wherever they are.

* 3G technology is emerging and growing day by day. Nobody can resist its charming temptation because it brings more convenience than ever.

[1] Marketing Strategic By Walker Mullin and Boyd Larreche

\section{References}

www.3g.co.uk

www.marketing.about.com

www.mobilein.com/3G.htm

www.online.vodafone.co.uk

www.three-g.net/3g_standards.html

www.vodafone.co.uk 